\title{
Metabolic stereoisomeric inversion of ibuprofen in mammals
}

\author{
Ching-Shih Chen ', Woan-Ru Shieh ', Pei-Heng Lu ', Shawn Harriman ' \\ and Ching-Yu Chen ${ }^{2}$ \\ 'Department of Pharmacognosy and Entironmental Health Sciences, College of Pharmacy, Unit ersity of Rhode Island, Kingston, RI \\ (U.S.A.) and' Department of Family Medicine, College of Medicine, National Taiwan Unit ersity. Taipei (Taiwan, Republic of China)
}

(Received 7 December 1990)

(Revised manuscript received 29 March 1991)

Key words: Stereoselective drug metabolism; lbuprofen isomerization; 2-Arylpropionyl-CoA epimerase

Studies on the mechanism and enzymology of metabolic ibuprofen isomerization constituted the focus of this investigation. Comparative in vivo studies revealed that this biotransformation proceeded via a proton abstraction mechanism in all tested species of mammals, which is in agreement with the previous reports. Direet evidence supporting this conclusion stemmed from the in vitro epimerization of ibuprofen-CoA thioester in rat liver homogenates. Chemically synthesized $(R)$-ihuprofen-CoA thioester was rapidly transformed to its $(S)$-counterpart by subcellular hepatic preparations. Examination of this epimerase activity in various rat tissue homogenates indicated that this enzyme was highly tissue specific. This biochemical reaction mainly took place in the liver and kidney, whereas low levels of enzyme activity were associated with other tissues. Nevertheless, the liver and kidney homogenates failed to invert $(R)$-ibuprofen directly even in the presence of all the necessary cofactors. Presumably, the failure to characterize this bioconversion was due to the lack of enzymatic acyl-CoA synthesis in these homogenates. It is noteworthy that the '2-aryipropionyl-CoA epimerase' catalyzed the transformation from either direction and with high turnover rates. The catalytic efinciency of $(S)$-ibuprofen CoA epimerization appeared to be greater than that of the $(R)$-counterpart. These in vitro findings suggest that the step of acyl-CoA formation assume a pivotal role in controlling the stereoselectivity and efficiency of the in vivo metabolism. As the responsible acyl-CoA synthetase(s) in different species of animals may exert the reaction with different degrees of enantiomeric preference and eficiency, the resulting stereochemical outcome and metabolic rates of this bioinversion vary accordingly. Consequently, in guinea pigs, this biotransformation proceeds in both directions with nearly equal efiiciency, whereas it is virtually unidirectional and slow in humans. Currently, the purification and characterization of this novel '2-arylpropionyl-CoA epimerase' from rat livers constitute the focus of this investigation.

\section{Introduction}

The biochemical isomerization of 2-arylpropionic acids represents an intriguing example of stereoselective biotransformation $[1,2]$. In the body, the $(R)$-antipode which is pharmacologically inactive undergoes stereochemical inversion to form its active $(S)$-isomer. Essentially, this metabolic inversion accounts for a bioactivation process, and may contribute to enhancing the adverse consequences of these therapeutic agents in metabolically compromised patients. For instance, it has been reported that various types of acute kidney failure could be elicited by short-term use of ibuprofen

Correspondence: C.S. Chen, Department of Pharmacognosy, College of Pharmacy, University of Rhode Island, Kingston. RI 02881, U.S.A. in patients with mild renal dysfunction $[3,4]$. Consequently, the biochemical and clinical implications of this metabolic reaction warrant close scrutinization. To date, although extensive pharmacokinetic studies on this bioconversion have been conducted [1,2,5], existing data on the enzymology and mechansim are still lacking or rather fragmentary. Several lines of evidence obtained from both in vivo $[6,7]$ and in vitro $[8,9]$ experiments have indicated that ibuprofen epimerization proceeds via proton abstraction at the $\mathrm{C}-2$. More recently, Sanins et al. [9] and Muller et al. [10] have demonstrated the biochemical inversion of ibuprofen in isolated rat hepatocytes. Nonetheless, a number of questions still remain unclear regarding this biochemical process: (a) Do all species of mammals share the same general mechanism of epimerization? (b) Is this metabolic inversion truly unidirectional? (c) What en- 
zymes are involved in this bioconversion and which enzymatic step effects the stereochemical discrimination? (d) What organs are responsible for this biotransformation? Therefore, this study was directed toward providing useful insight into these questions to gain better understanding of this unique metabolism.

\section{Materials and Methods}

\section{Chemicals}

Racemic ibuprofen (2-(4'-isobutylphenyl)propionic acid) was prepared from commercial ibuprofen tablets and further purified by recrystallization from petroleum ether. Racemic $\left[3,3,3-{ }^{2} \mathrm{H}\right]$ ibuprofen and $\left[2-{ }^{2} \mathrm{H}\right]$ ibuprofen were synthesized according to the procedures previously described [11]. Optically active ibuprofen and its deuterated derivatives were prepared by the enzymatic resolution of the corresponding racemic methyl esters [11]. The enantiomeric excess (ee) of these optically enriched compounds was no less than $97 \%$. Calculation of ee was based on the equation, ee $=(A-$ $B) /(A+B)$, where $A$ and $B$ are the concentrations of the major and minor isomers, respectively.

The CoA thioesters of $(R)$ - and $(S)$-ibuprofen were synthesized from the mixed anhydride of the corresponding acids by a modification of the method described by Goldman and Vagelos [12]. In a typical experiment, to a solution of dry methylene chloride (15 $\mathrm{ml})$ containing optically active ibuprofen $(0.56 \mathrm{~mol})$ and 2,6-lutidine $(0.56 \mathrm{~mol})$ was added ethyl chloroformate $(0.56 \mathrm{~mol})$ in methylene chloride $(5 \mathrm{ml})$. The mixture was stirred at room temperature for $30 \mathrm{~min}$, and was then taken to dryness under reduced pressure. The residue was dissolved in $13 \mathrm{ml}$ of freshly distilled tetrahydrofuran and added dropwise to $13 \mathrm{ml}$ of water solution ( $\mathrm{pH} 7.5$ ) containing $100 \mathrm{mg}$ of $\mathrm{CoA}$. The $\mathrm{pH}$ of the solution was maintained $27.2-7.5$ by adding $0.5 \mathrm{M}$ $\mathrm{NaOH}$. After stirring at $25^{\circ} \mathrm{C}$ for $15 \mathrm{~min}$, the solution was acidified to $\mathrm{pH} 5$ with $1 \%$ perchloric acid and most of the tetrahydrofuran was removed under reduced pressure. The aqueous solution was further treated with $1 \mathrm{ml}$ of $10 \%$ perciloric acid and the precipitate was collected by centrifugation at $12000 \times g$ for 10 min. The resulting precipitate was washed consecutively with $5 \mathrm{ml}$ of $1 \%$ perchloric acid, acetone-ethyl ether $(1: 2)$ and ethyl ether to remove unreacted $\operatorname{CoA}$ and ibuprofen, respectively. The chemical yields ranged from 40 to $50 \%$ based on the amount of CoA added. This chemically synthesized $C O A$ thioester gave a single UV-absorbing spot with an $R_{f}$ of 0.8 on thin layer cellulose plates (butanol-acetic acid- $\mathrm{H}_{2} \mathrm{O}, 10: 3: 5$, $v / v)$, indicating no free $\operatorname{CoA}\left(R_{\mathrm{f}} \approx 0.2\right)$ remaining in the sample. The acid moiety was liberated from the thioester by treating the compound with hydroxylamine, followed by $\mathrm{HCl}$ hydrolysis. Subsequent enantioselective HPLC analysis of the resulting acid accord- ing to the method described below revealed that no appreciable racemization of ibuprofeil occurrcd during the synthesis. The procedure for preparing the hydroxamic acid standard was essentially the same as described above except that $\operatorname{COA}$ was replaced by five equivalents of thydroxylamine and the reaction was terminated by extracting the solucion three times with equal vols. of ethyl acetate. The resulting hydroxamic acid derivative was purified by silica gel chromatography (hexane-ethyl acetate, 1:1). 'H-NMR (90 MHz, $\left.\mathrm{CDCl}_{3}\right) 1.06(\mathrm{~d}, 6 \mathrm{H}, J=7.5 \mathrm{~Hz}), 1.63(\mathrm{~d}, 3 \mathrm{H}, J=7.5$ $\mathrm{Hz}), 1.78-2.35(\mathrm{~m}, 1 \mathrm{H}), 2.6(\mathrm{~d}, 2 \mathrm{H}, J=6 \mathrm{~Hz}), 3.62$ (q, $1 \mathrm{H}, J=7.5,12 \mathrm{~Hz}), 7.29(\mathrm{~s}, 4 \mathrm{H}), 8.0-9.0(\mathrm{br}, 1 \mathrm{H})$.

All other chemical and biochemical reagents and solvents were obtained from commercial sources. The chemical structures of optically active ibuprofen and its derivatives mentioned in this paper are summarized in Fig. 1.

\section{Drug administration and sample collection}

Male Wistar rats $(225-250 \mathrm{~g})$ and Hartley guinea pigs $(201-250 \mathrm{~g})$ of either sex were obtained from Charles River Laboratories (Wilmington, MA). Dutch male rabbits $(2-3 \mathrm{~kg})$ were supplied by Mill Brook Farm (Amherst, MA). These animals were fasted for $12 \mathrm{~h}$ before drug administration. Each animal received optically active ibuprofen orally as a $1 \%$ aqueous fine suspension containing $0.05 \%$ Tween 80 through gavage. As the pharmacokinetic behavior of ibuprofen in different species of animals varied [5], it was found that, under these conditions, the optimal times for recovering the metabolites from the sera after dosing were approx. $30 \mathrm{~min}, 30 \mathrm{~min}$ and $15 \mathrm{~min}$ for rats, guinea pigs and rabbits, respectively. The rats and guinea pigs were then anesthetized with diethyl ether and the rabbits were treated with ketamine, (2-(2-chlorophenyl)-2-(methylamino)-cyclohexanone), (50 $\mathrm{mg} / \mathrm{kg}$ ). Total blood was withdrawn from the portal vein with a heparinized syringe. The plasma was immediately separated by centrifugation $(12000 \times \mathrm{g}, 20 \mathrm{~min})$ at $4^{\circ} \mathrm{C}$ for further analysis.

The human metabolic study was conducted in National Taiwan University Hospital. This study received approval from the Institutional Review Board on Human Subjects of both institutions prior to the experiment. Four healthy adult volunteers participated in the study. All the subjects were Oriental, with ages ranging from 25 to 37 years old. The subjects were in $:$ ructed to fast for $12 \mathrm{~h}$ before the start of the study. Each subject received capsules containing $800 \mathrm{mg}$ of optically active ibuprofen. At $30 \mathrm{~min}, 1 \mathrm{~h}$ and $2 \mathrm{~h}$ after the drug administration, $10 \mathrm{ml}$ blood samples were collected by individual peripheral venopunctures with heparinized syringes. The plasma was prepared by centrifugation at $2500 \mathrm{rpm}$ for $10 \mathrm{~min}$ for further analysis. 
Isolation and enantioselectite HPLC analysis of ibuprofen metabolites in plasma

The plasma samples were acidified with i $\mathrm{M} \mathrm{HCl}$ to $\mathrm{pH} 1$, and heated in a boiling water bath for $10 \mathrm{~min}$. The resulting turbid solution was saturated with sodium chloride, and extracted three times with equal vols. of ethyl acetate. The organic solvent fractions were combined, dried over anhydrous sodium sulfate and concentrated under reduced pressure. To the residue was added three drops of thionyl chloride, and the mixture was incubated at $60^{\circ} \mathrm{C}$ for $30 \mathrm{~min}$. The remaining thionyl chloride was removed under reduced pressure. $(1 R, 2 S, 5 R)-(-)$-Menthol $(5 \mathrm{mg})$, dissolved in $100 \mu \mathrm{l}$ of methylene chloride and 1 drop of pyridine were then added to the residue. The solution stood at room teriperature for $15 \mathrm{~min}$ and was passed through silica gel $(1, g)$ fitted in a pasteur pipette. The column was eluted with $6 \mathrm{ml}$ of hexane-diethyl ether $(20: 1)$ and the collected solvent was evaporated under a stream of nitrogen. The resulting menthyl esters were analyzed by HPLC using a Model 501 pump (Waters Associates) equipped with a Rheodyne injector, two Whatman Partisil columns $(10 \mu)$ in tandem $(2 \times 4.6 \mathrm{~mm} \times 25$ $\mathrm{cm}$ ) and a Model $481 \mathrm{UV} / \mathrm{Vis}$ detector (Waters Associate). The columns were eluted with a mobile phase consisting of haxane-diethyl ether $(100: 1)$ at a flow rate of $0.8 \mathrm{ml} / \mathrm{min}$. The retention times for the menthyl esters were: $R$-ibuprofen: $29 \min 50 \mathrm{~s} ; S$-ibuprofen: 32 min; R-tert-hydroxyibuprofen: $33 \mathrm{~min} 40 \mathrm{~s}$; $S$-tert-hydroxyibuprofen: $36 \mathrm{~min}$. Low resolution electron impact (EI) and chemical ionization $(\mathrm{Cl})$ mass spectra of these eluted compounds were obtained on a Kratos MS-80RFA spectrometer, Chemical Instrument Center, Yale University.

Preparation of rat tissue homogenates and in citro incubation

Wistar male rats $(225-250 \mathrm{~g})$ were sacrificed by decapitation after light ether anesthesia. Liver, lung. heqrt, kidneys, intestine and skeletal muscle were removed, and rinsed with chilled saline solution ( $\mathrm{pH} 7.2$ ). The tissues were homogenized in 2.5 times $(\mathrm{v} / \mathrm{w})$ the tissue weight of $10 \mathrm{mM}$ potassium phosphate buffer (pH 7.2) containing $5 \%(w / v)$ sucrose and $0.5 \mathrm{mM}$ p-toluenesulfonyl fluoride (PMSF) [13] with a motorized tissue homogenizer at $4^{\circ} \mathrm{C}$. The resulting homogenates were centrifuged at $10000 \times g$ for $10 \mathrm{~min}$ at $4^{\circ} \mathrm{C}$ to remove tissue debris. Protein assays were performed by the Coomassie blue dye-binding method using a commercial protein assay reagent (Pierce Chemical) with bovine serum albumin (Sigma) as a standard.

In our intial experiment, $(R)$-ibuprofen $(1 \mathrm{mM})$ was incubated with rat liver homogenates $(120 \mathrm{mg}$ protein $/ \mathrm{ml})$ in the presence of ATP $(10 \mathrm{mM}), \mathrm{Mg}^{2+}$ (15 mM), and CoA (1.2 mM). After incubating the mixture for $1 \mathrm{~h}$, hydroxylamine was added as a trapping agent [14] for acyl-CoA thiocsters. The reaction mixture was extracted three times with equal vols. of ethyl acetate. Essentially. upon adding hydroxylamine, any acyl-CoA generated could be readily converted to the corresponding hydroxamic acid which is soluble in organic solvents. In the acyl-CoA experiment, to $10 \mathrm{ml}$ of freshly prepared tissue homogenates with appropriate dilutions was added chemically synthesized $R$-ibuprofen CoA $(5 \mu \mathrm{mol})$ dissulved in $0.5 \mathrm{ml}$ of $250 \mathrm{mM}$ potassium phosphate buffer ( $\mathrm{pH} 7.2$ ). After incubating the mixture at $25^{\circ} \mathrm{C}$ for various time intervals, the reaction was terminated by adding $4 \mathrm{ml}$ of $2.8 \mathrm{M}$ hydroxylamine solution ( $\mathrm{pH} 7.0)$. As indicated from cellulose and silica gel TLC, virtually all the thiouster was converted to the corresponding hydroxamic acid after $5 \mathrm{~min}$. The resulting ibuprofen hydroxamic acid was extracted from the solution with ethyl acetate, followed by $6 \mathrm{M} \mathrm{HCl}$ hydrolysis to afford free ibuprofen. The acid was then converted to its corresponding menthyl ester and the enantiomeric composition was determined accordingly. The diastereomers were quantitated by reference to a calibration curve. It was assumed that ibuprofen and its tert-alcohol had identical extinction coefficients.

\section{Results}

Mechanism of ibuprofen epimerization in rabbits and guinea pigs

( $R$ ) $-\left[3,3,3-{ }^{2} \mathrm{H}\right]$ ibuprofen and $(R)-\left[2-{ }^{2} \mathrm{H}\right]$ ibuprofen were orally administered to rabbits and guinea pigs, respectively. Thus, monitoring the loss of deuterium from these deuterated molecules allowed a direct assessment of the epimerization mechanism. Unchanged ibuprofen and its tert-hydroxy metabolite were isolated from the plasma and subjected to enantioselective HPLC separation after being converted to their diastereomeric (l)-menthyl derivatives. The molecular species of these purified compounds were then identified by mass spectral analysis. The results derived from both animals were virtually identical and were in line with the data reported for humans [6] and rats [7]. When $(R)-\left[2-{ }^{2}\right.$ H]ibuprofen was used as the substrate. loss of the deutcrium label was observed in the resulting $(S)$-ibuprofen and its tert-hydroxy derivative: whereas for the $(S)$-ibuprofen derived from $(R)$-[3.3,3:H]ibuprofen metabolism. all the three deuterium atoms were retained.

In cito study on the stereochemcial preference of ibuprofen epimerization

In general, this metabolic event has been assumed to be a highly stereoselective process, i.e., from $R$ to $S$ but not vice versa. Lately. evidence regarding the occurrence of the reverse reaction has been presented to 

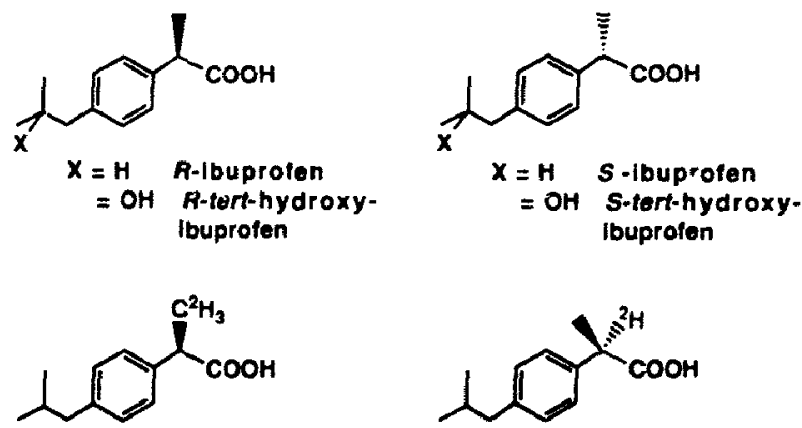

$A \cdot\left[3,3,3={ }^{2} \mathrm{H}\right]$ ibuprofen<smiles>CC(C)Cc1ccc([C@@H](C)C(=O)O)cc1</smiles>

$X=$ SCoA R-tbuproten CoA

= NHOH R-Ibuprofen hydroxamic acid

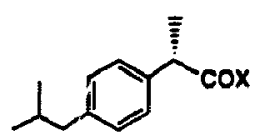

$X=$ SCOA S-ibuproten CoA

$=$ NHOH S-ibuprofon hydroxamic acid

Fig. 1. Chemical structures of compounds referred to in the text.

dispute this assumption $[7,15]$. In this study, in light of possible species variation arising from differences in the disposition routes [16], this stereoselective metabolism was scrutinized in four different animal species including rats, guinea pigs, rabbits and humans. It has been documented that in humans, rabbits and guinea pigs, renal excretion accounts for the major clearance of the 2-arylpropionates, whereas rats excrete the compounds mainly in the feces via the bile [16].

In each experiment, $(R)$ - and $(S)$-ibuprofen were orally administered to different subjects of the same species, respectively. Ibuprofen and its tert-hydroxy metabolite were then isolated from the sera and subjected to stereoselective HPLC analysis. As depicted in Table I, significant discrepancy in the efficiency and stereochemical outcome of this biotransformation was observed among these animals. In humans, this biochemical reaction was virtually unidirectional and appeared to be slower than other animals, which is in agreement with the previous reports $[17,18]$. Even though trace amounts of $R$-ibuprofen and its corresponding tert-alcohol were detected from $(S)$-ibuprofen metabolism in humans, they might arise from the slight optical impurity in the $(S)$-ibuprofen r -eparation $(\mathrm{ee}=97 \%)$. In contras, inversion of both $(R)$ - and $(S)$-ibuprofen with nearly the same efficiency, and were the most efficient inverter among the animals iested. In both rats and rabbits, ( $S$ )-ibuprofen metabolism gave rise to small but significant levels of $(R)$-antipodes.

\section{In ivitro metabolic epimerization of ibuprofen}

In an attempt to further substantiate the mechanism elucidated from the in vivo experiments, we turned our attention toward the development of active subcellular preparations. Recently, the occurrence of this metabolic event in isolated rat hepatocytes has been demonstrated $[9,10]$, which agrees with the general supposition derived from the pharmacokinetic studies that the liver and kidney are the major organs responsible for this bioconversion [19]. Nonetheless, in our study, when ibuprofen was incubated with iiver homogenates in the presence of all the necessary cofactors, no acyl-CoA formation was detected by the hydroxylamine trapping method, nor were changes in the enantiomeric compo-

\section{TABLE I}

Percent plasma distributions of $R$ - and S-ibuprofen and their corresponding tert-hydron metabolites following oral administration of antipodal ibuprofen to a arious animals "

\begin{tabular}{|c|c|c|c|c|c|c|c|c|}
\hline \multirow{2}{*}{$\begin{array}{l}\text { Antipode } \\
\text { administered } \\
c_{t} \text { Distribution } \\
\text { in plasma }\end{array}$} & \multicolumn{4}{|c|}{$R$-Ibuprofen } & \multicolumn{4}{|c|}{ S. Thuprofen } \\
\hline & $R$-lbu & $S$-Ibu & $\begin{array}{l}t-\mathrm{OH} \\
R \text {-lhu }\end{array}$ & $\begin{array}{l}\text { P.OH } \\
\text { S-lhu }\end{array}$ & $R \cdot \mathrm{lbu}$ & $S$-Ibu & $\begin{array}{l}l-\mathrm{OH} \\
R-1 \mathrm{Bu}\end{array}$ & $\begin{array}{l}t \cdot \mathrm{OH} \\
S \text {-Ibu }\end{array}$ \\
\hline $\begin{array}{l}\text { Rats } \\
(n=3)\end{array}$ & $\begin{array}{r}8.2 \\
( \pm 1.2)\end{array}$ & $\begin{array}{c}5.3 \\
( \pm 0.7)\end{array}$ & $\begin{array}{c}56.5 \\
( \pm 7.8)\end{array}$ & $\begin{array}{c}30.0 \\
( \pm 5.4)\end{array}$ & $\begin{array}{c}3.5 \\
( \pm 1.2)\end{array}$ & $\begin{array}{c}23.9 \\
( \pm 5.4)\end{array}$ & $\begin{array}{r}5.8 \\
( \pm 1.1)\end{array}$ & $\begin{array}{r}66.8 \\
(+8.5)\end{array}$ \\
\hline $\begin{array}{l}\text { Guinea pigs } \\
(n=3)\end{array}$ & $\begin{array}{c}25.4 \\
( \pm 2.8)\end{array}$ & $\begin{array}{c}36.5 \\
( \pm 5.2)\end{array}$ & $\begin{array}{c}18.4 \\
(+3.5)\end{array}$ & $\begin{array}{c}19.7 \\
( \pm 1.9)\end{array}$ & $\begin{array}{c}19.2 \\
( \pm 3.2)\end{array}$ & $\begin{array}{r}37.9 \\
( \pm 7.8)\end{array}$ & $\begin{array}{r}7.0 \\
( \pm 1.5)\end{array}$ & $\begin{array}{c}35.9 \\
( \pm 9.8)\end{array}$ \\
\hline $\begin{array}{l}\text { Rabbits } \\
(y:=3)\end{array}$ & $\begin{array}{c}20.8 \\
( \pm 3.4)\end{array}$ & $\begin{array}{r}7.7 \\
( \pm 1.2)\end{array}$ & $\begin{array}{r}44.6 \\
( \pm 7.7)\end{array}$ & $\begin{array}{c}26.9 \\
(+5.2)\end{array}$ & $\begin{array}{r}4.5 \\
( \pm 0.7)\end{array}$ & $\begin{array}{c}16.9 \\
( \pm 2.5)\end{array}$ & $\begin{array}{c}11.0 \\
( \pm 2.1\}\end{array}$ & $\begin{array}{r}67.6 \\
( \pm 12.3)\end{array}$ \\
\hline $\begin{array}{l}\text { Humans } \\
(n=4)\end{array}$ & $\begin{array}{c}32.0 \\
( \pm 7.8)\end{array}$ & $\begin{array}{r}6.9 \\
(+1.5)\end{array}$ & $\begin{array}{r}46.3 \\
(+9.2)\end{array}$ & $\begin{array}{c}14.8 \\
( \pm 3.7)\end{array}$ & $<2$ & $\begin{array}{r}25 \\
( \pm 11)\end{array}$ & $<2 d$ & $\begin{array}{r}71 \\
( \pm 13)\end{array}$ \\
\hline
\end{tabular}

\footnotetext{
"The plasma samples were prepared at $30,15,30$ and $120 \mathrm{~min}$ after dosing for rats, rabbits, gunea pigs and humans. respectively according to the procedure der zribed under "Materials and Methods".

Ihu: ibuprofen: $t-\mathrm{OH}$ lbu: tert-hydroxylated ibuprofen

c Valucs represent the mean of three to four subjects.

"The values can not be determined accurately dec to the presence of minute quantities of interfering impurities.
} 
sition of the recovered ibuprofen noted (ee $\geq 97 \%$ ). The lack of bioconversion of ibuprofen prompted us to examine this metabolic transformation using ibuprofen-CoA thioester as the substrate. Evidently, this thioester substrate could allow us to bypass the enzymatic acyl-CoA formation and to assess the epimerization directly.

The chemically synthesized CoA thioester of $(R)$ ibuprofen was incubated with rat liver homogenates without the addition of any cofactor. Only small amounts of ibuprofen were detected after incubating the mixture for $2 \mathrm{~h}$, indicating the presence of weak thioesterase activity in the subcellular preparations. At various time intervals, the $\mathrm{CoA}$ ester in the solution was recovered as its corresponding hydroxamic acid which was then subjected to acid hydrolysis to yield ibuprofen. Enantioselective HPLC analysis of the recover d ibuprofen revealed rapid declines in the $R / S$ ratio. As evidenced from Fig. $2 \mathrm{~A}$ and $\mathrm{B}$, the extents of conversion depended on both protein concentration and incubation time. This enzyme preparation also catalyzed the epimerization of $(S)$-ibuprofen-CoA with even greater efficiency under the same conditions. The apparent catalytic rates were 0.24 and $0.60 \mu \mathrm{mol} / 5$ min per $\mathrm{mg}$ protein for $(R)$ - and $(S)$-ibuprofen-CoA, respectively, in crude liver homogenates. Also, it is interesting to note that this epimerization reaction reached an equilibrium slightly in favor of $(R)$-ibuprofen-CoA, of which the biochemical significance remains to be explored. The speculative role of a nonenzymatic process [1] in effecting the inversion was excluded by the control experiment where $(R)$-ibuprofen$\mathrm{CoA}$ ester was exposed to a boiled enzyme preparation. Even after prolonged incubations, no appreciable amounts of $(S)$-ibuprofen-CoA could be detected.

\section{Identification of organs responsible for ibuprofen epimer- ization}

Tissue homogenates prepared from rat kidney, intestine, heart, lung and muscle were tested for the epimerase activity. Table II thus shows the apparent conversion rates of both $(R)$ - and $(S)$-ibuprofen-CoA esters in various cell-free preparations. As shown, this biotransformation mainly occurs in the liver and $k: \mathrm{J}$. ney. Only low levels of epimerase activity were detected in other tissues, accounting for approx. $5 \%$ of that in the liver or kidney. It should be noted that, in all the tissues tested, the apparent conversion rates for $(S)$-ibuprofen-CoA were higher than those for the $R$ counterparts, and the ratios of these two rates appeared to be consistent (approx. 2.5).

\section{Discussion}

To date, three distinct proposals $[1,2]$ have been raised to account for this epimerization mechanism. in
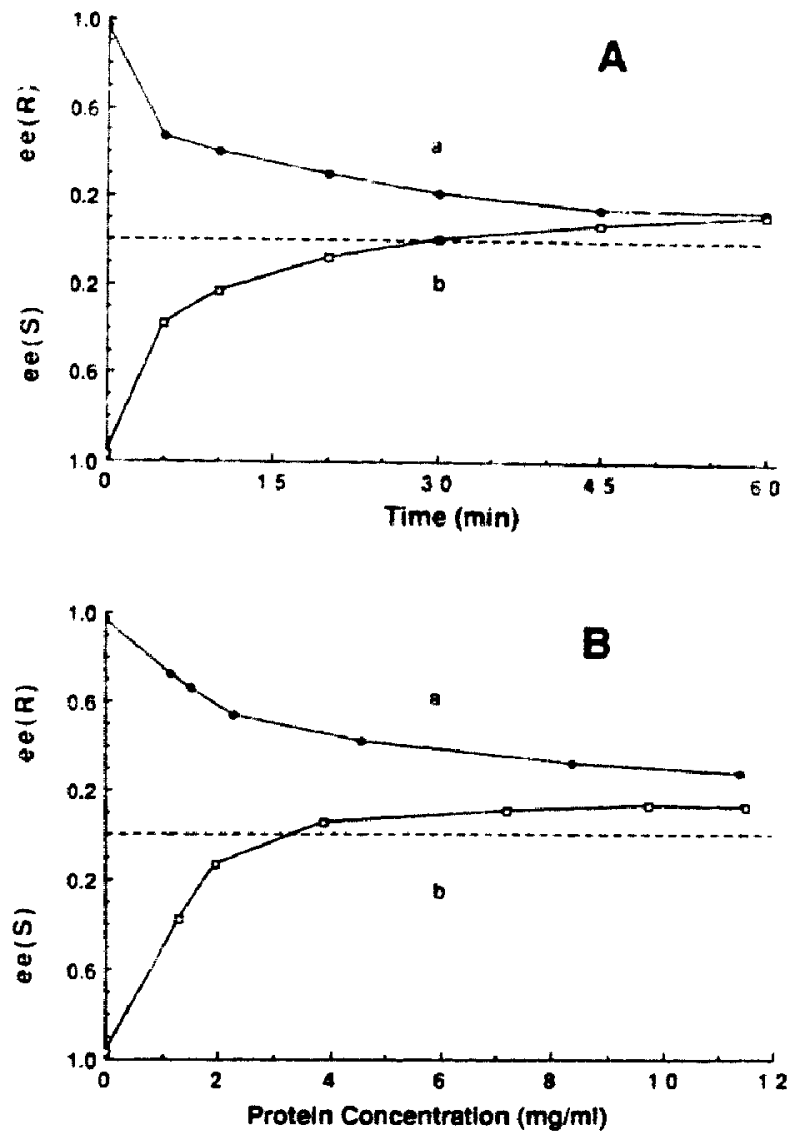

Fig. 2. Ibuprofen-CoA epimerization as a function of (A) time and (B) of protein concentration. In the time-dependency study (A), curve a represents the enzymatic inversion of $R$-ibuprofen-COA in $r$ at liver homogenates. The thioester $(2.5 \mu \mathrm{mol})$ was incubated with 5 $\mathrm{ml}$ of the cell free preparation $(2.8 \mathrm{mg}$ protein $/ \mathrm{ml}$ ) for the indicated time intervals and the reaction was terminated by adding $2 \mathrm{ml}$ of 2.8 M hydroxylamine (pH 7.0) to the solution. The enantiomeric composition of the resulting ibuprofen was determined according to the procedure described under Materials and Methods. Curve $b$ is the progressive curve for $S$-ibuprofen-CoA inversion. The experimental conditions were virtually the same as described above except that the concentration of the liver homogenate was $1.5 \mathrm{mg} / \mathrm{ml}$. In the protein concentration profile (B), $R$ - and $S$-ibuprofen-CoA $(2.5 \mu \mathrm{mol})$, represented by curves $a$ and $b$, respectively, were exposed to $5 \mathrm{ml}$ of liver homogenates with various dilutions. The mixture was incubated for $5 \mathrm{~min}$ and the reaction was terminated according to the aforementioned procedure. Experimental details are described under Materials and Methods. The experimental values are the mean of duplicate determinations from two separate experiments. $\bullet R$ ibuprofen-COA: O, S-ibuprofen-COA

which the nature of the reaction intermediate constitutes the focus of dispute. Nonetheless, based on the present evidence and the previously reported data [69], the proton abstraction mechanism appears to be responsible for this metabolic event in all tested species of mammals despite marked discrepancy in their pharmacokinetic behavior. The alternative oxidoreductive mechanisms are clearly refuted by the results from the deuterium-labeling studies. In addition, direct evidence 
giving support to this view came from the in vitro epimerization of ibuprofen-COA thioester in liver subcellular preparations. Fig. 2 clearly illustrates the pivsal role of 2-arylpropionyl-CoA epimerase in catalyzing the configurational inversion. It is interesting to note that the epimerase mediates the conversion from either direction.

$$
\begin{aligned}
& \text { 2-arylpropionyl-CoA }
\end{aligned}
$$

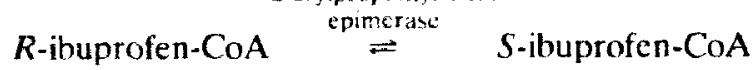

Rclatively, the catalytic efficiency of $(S)$-ibuprofen-CoA epimerization is greater than that of the $(R)$-counterpart, which is in line with the observation that the reaction attained equilibrium in favor of $(R)$-ibuprofen-CoA.

Examination of this epimerase activity in various tissue subcellular preparations indicated that the enzyme was high.ly tissue specific. This reaction mainly took place in the liver and kidney, whereas only low levels of enzyme activity were associat id with other tissues. This finding is in favor of the systemic transformation proposed by several investigators $[19,20]$. Nevertheless, even though the inversion occurs in a systemic manner, a progressive increase in the $S / R$ ratio upon the administration of the $(R)$-isomer may not be observed due to the reversible nature of this reaction, which contradicts the kinetic model formulated by Jamali and his co-workers [21]. In our previous report [7] in which the time course of $(R)$-ibuprofen metabolism in rats was studied, the $S / R$ ratios of the recovered ibuprofen and its tert-hydroxy metabolite appeared to be unchanged within the period of investigation $(90$ $\min )$. Presumably, during the inversion, the CoA thioester formation inside the cells is the rate-limiting step and the subsequent epimerization reaches an equilibrium almost instantaneously. This speculation is rurrently under investigation in this laboratory using an in vivo NMR technique.
On the other hand, attempts to effect ibuprofen racemization in tissue homogenates were not successful in this study even when all the necessary cofactors were present. This is consistent with the results reported by a number of groups [22-24]. Apparently, the failure to charactetize this bioconversion results from the lack of enzymatic acyl-CoA synthesis in the homogenates. Many acyl-CoA synthetases displaying distinct substrate specificity have been identified in mammalian cells [25-28]. As most of these activities are associated with the sarticulate fractions, it is probable that the responsiblc enzyme(s) fails to gain access to the substrate and/or cofactors due to the compartmentational arrangement of the membrane structures.

In addition, as implied by the poor stereochemical discrimination in the epimerase catalysis, the step of acyl-CoA formation assumes a crucial role in controlling the stereoselectivity and turnover rate of this metabolism. This conclusion is supported by the recent evidence of stereoselective ibuprofen-CoA formation catalyzed by rat liver microsomes $[29,30]$. Nevertheless, it is possible that the responsible acyl-CoA synthetase(s) in different species of animals may exert the reaction with different degrees of enantiomeric preference and efficiency. As a consequence, the resulting stereochemical outcome of this metabolic inversion varies accordingly. As shown in Table I, for animals such as guinea pigs, this biotransformation proceeds in both directions with nearly the same efficiency, whereas it is virtually unidirectional in humans. In addition, the species variation in the rate of metabolic inversion may also be accounted for by the catalytic efficiency of the thioester synthetases in different animals.

A final note regarding the hydroxylamine trapping technique employed in this study is that it provides a facile method for isolating the acid moiety from acylCoA under mild and neutral conditions, since CoA thioester can not easily be recovered. One ought to bear in mind that since the alpha-proton of ibuprofen

TABLE II

Apparent Rates of $R$ - and $S$-ihuprofen.CoA epimerization in tarious rat tissue homogenates "

\begin{tabular}{|c|c|c|c|}
\hline & $\begin{array}{l}S \text {-ibuprofen-CoA } \\
(\mu \mathrm{mol} / \mathrm{mg} \text { protein per } 5 \mathrm{~min})\end{array}$ & $\begin{array}{l}R \text {-ibuprofen-CoA } \\
(\mu \mathrm{mol} / \mathrm{mg} \text { protein per } 5 \mathrm{~min})\end{array}$ & $V_{S} / V_{R}{ }^{h}$ \\
\hline Liver & $0.60 \pm 0.07$ & $0.24 \pm 0.02$ & 2.5 \\
\hline Kidney & $0.95 \pm 0.03$ & $0.37 \pm 0.02$ & 2.6 \\
\hline Intestine & $0.025 \pm 0.006$ & $0.011 \pm 0.003$ & 2.3 \\
\hline Muscle & $0.037 \pm 0.004$ & $0.015 \pm 0.004$ & 2.5 \\
\hline Lung & $0.043 \pm 0.011$ & $0.017 \pm 0.005$ & 2.5 \\
\hline Heart & $0.045 \pm 0.01 .3$ & $0.020 \pm 0.008$ & 2.3 \\
\hline
\end{tabular}

" $R$ - and $S$-ibuprofen-CoA were cxposed to various tissue homogenates with appropriate dilutions. respectively. The mixture was incubated at $25^{\circ} \mathrm{C}$ for $5 \mathrm{~min}$, and the reaction was terminated by adding hydroxylamine to the solution. Experimental details are described under Materials and Methods.

${ }^{n} V_{S} / V_{R}$ is the ratio of the apparent conversion rate of $S$-ibuprofen-CoA to that of the $R$-counterpart. 
thioester is fairly acidic $\left(\mathrm{p} K_{\mathrm{a}} \approx 10.3\right)$ [7], alkaline treatments to hydrolyze the acyl-CoA may lead to concomitant chemical racemization. On the other hand, it was indicated in our experiments that the acid hydrolysis gave rise to several unidentified impurities which might derive from $\mathrm{CoA}$ fragments. These contaminants caused interference in the subsequent HPLC analysis.

In summary, the following conclusions can be put forth from the present study: (a) this metabolic inversion proceeds via a proton abstraction process mediated by a CoA-dependent epimerase whose identity still remains unclear; (b) the liver and kidney are the major organs where this bioconversion takes place; (c) since the epimerase-mediated reaction is reversible, stereoselectivity control of this metabolism lies in the step of acyl-CoA synthesis; therefore, (d) as reflected from the enantiomeric preference of the responsible acyl-CoA synthetase(s), individual species of animals exert the metabolic inversion with different degrees of stereochemical selectivity and efficienc;

At present, the purification and characterization of this '2-arylpropionyl-CoA epimerase' from rat livers represent the focus of this irvestigation and the progress will be reported duly.

\section{Acknowledgements}

This investigation was supported in part by a Research Starter Grant from Pharmaceutical Manufacturers Association Foundation and a Research Grant, GM39236, from the National Institutes of Health.

\section{References}

1 Hutt. A.J. and Caldwell, J. (1983) J. Pharm. Pharmacol. 35. 693-704.

2 Caldwell, J.. Hutt. A.J. and Fournel-Giglfux. S. (1988) Biochem. Pharmacol. 37, 105-114.

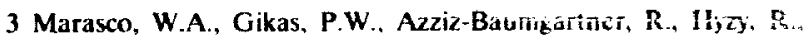
Eldredge, C.I. and Stross. J. (1987) Arch. Intern. Med. 147. 2107-2116.

4 Whelton. A., Stout, R.L.. Spilman, P.S. and Kalssen, D. K. (1990) Ann. Intern. Med. 112, 568-576.

5 Hucker. H.B., Kwan, K.C. and Duggan, D.E (1980) in Progress in
Drug Metabolism (Bridges. J.W. and Chasseáud, L.F., eds.). Vo: 5. pp. 165-253. John Wiley \& Sons, New York.

6 Baillie. T.A., Adams. W.J. Kaiser, D.G. Olanoff, L.S., Halstead. G.W.. Harpootlian. H. and VanGiessen. G.J. (1989) J Pharmacol. Exp. Ther. 249, 517-523.

7 Rats: Chen. C.S. Chen. T, and Shich. W.-R. (1990) Biochim Biophys. Acta 1033, 1-6.

8 Nakamura. Y., Yamaguchi. T. Takahashi, S. Hashimoto. S., Iwatani. K. and Nak'gawa, Y. (1981) J. Pharmacobio-Dyn. 4. s-1.

9 Sanins, S.M.. Ad amc, W.J. Kaiser, D.G.. Halstead, G.W, and Baillie, T.A. (19m) Drug Metab. and Dispos. 18, 527.

10 Multer. S.. May 'r. J M., Etter, J.C. and Testa. B. (1990) Chirality 2, 74-78.

11 Chen, C.-S. Copeland, D., Harriman, S. and Liu, Y.C. (1990) J Labeled Compd. Radiopharm. 28. 1017-1024

12 Goldman, P. and Vagelos, P.R. (1961) J. Biol. Chem. 236, 26202623.

13 Prouty W.F. and Goldberg, A.L. (1972) J. Biol. Chem. 247, 3341-3352.

14 Kornberg. A. and Pricer, W.E., Jr. (1953) J. Biol. Chem. 204, 329-343.

15 Fournel, S. and Caldwell, J. $(\$ \$ 86)$ Biochem. Pharmacol 35 4153-4159.

16 Chatfield. D. H. and Green. J. (1978) Xenobiotica 8, 133-144.

17 Wechter. W.J., Loughhead, D.G.. Reischer. R.J., VanGiessen, G.J. and Kaiser, D.G. (1974) Biochem. Biophys. Res. Commun. 61. 833-837

18 Kaiser, D.G., VanGiessen. G.J., Reischer. R.J. and Wechter, W.J. (1976) J. Pharm. Sci. 65, 26y-273.

19 Yamaguchi, T. and Nakamura. Y. (1987) Drug Metab. Dispos. 15. $535-539$.

20 Cox. T.W. Cox. S.R., VanGissen. G. and Ruwart, M.J. (1985) J Pharmacol. Exp. Ther. 232, 636-643.

21 Mahvar, R. and Jamali. F. (1988) Pharm. Res. 5, 76-79.

22 Simmonds, R.G. Woodage. T.J.. Duff, S.M and Green, J.N. (1980) Eup. J. Drug Metab. Pharmacokinet. S. 169-172.

23 Nakamura. Y. and Yamaguchi. T. (1987) Drug Metab. Dispos. 15. $529-534$

24 Mayer, J.M., Bartolucci, C., Maitre, J.M. and Testa. B. (1988) Xenobiotica 18, 533-543.

25 Killenberg. P.G.. Davidson. E.D. and Webster. L.T., Jr. (1971) Mol. Pharmacol. 7, 260-268.

26 Pande, S.V. and Mead, J. (1968) J. Biol. Chem. 243. 352-361.

27 Polokoff, M.A. and Bell, R.M. (1977) J. Biol. Chem. 252. 11671171.

26 Normann. P.T. Thomassen. M.S. Christiansen, E.N. azid Flatmark, T. (1981) Biochim. Biophys. Acta 664. 416-427.

29 Knihinicki. R.D. Williams. K.M. and Day. R.O. (1989) Biochem. Pharmacol. 38, 4389-4345.

30 Knatler. M.P. and Hall, S.D. 119901 Chirality $2,67-73$. 